\title{
AN ECONOMETRIC MODEL OF THE TOBACCO INDUSTRY
}

\author{
John M. Vernon, Norfleet W. Rives, Jr. and Thomas H. Naylor *
}

\section{Introduction}

$I^{1}$ $\mathrm{N}$ this paper we describe an econometric model of the American tobacco industry for the period 1949 through 1966. The model contains 19 equations and is divided into three major blocks - (1) leaf production, (2) leaf price, and (3) cigarettes.

The objective is to explain the behavior of the tobacco industry over an 18-year period. Ultimately, we hope to use the model to perform policy simulation experiments to evaluate the effects of alternative governmental and managerial policies on the behavior of the industry.

We begin with a brief description of the industry. Next we discuss the theoretical specification of the model and the statistically estimated equations. We conclude with some example simulation results which provide additional evidence of the validity of the model for explaining the behavior of the tobacco industry over the period 1949 through 1966.

\section{Description of the Industry}

The tobacco industry, as we will use the term in this paper, includes the growers of flue-cured tobacco leaf, the auction-warehouse system wherein the leaf is sold to the cigarette manufacturers, and the manufacture and sale of cigarettes to the public. We ignore the manufacture of other tobacco products.

There are a number of other types of tobacco leaf, e.g., Burley, Maryland, fire-cured, etc., which we have elected to ignore. ${ }^{1}$ Our justification is that flue-cured leaf is the most important in cigarette production. One estimate has placed the average blend of all domestic cigarettes as 49 per cent flue-cured and 37 per cent Burley [26, table 18]. Table 1 shows acreage and leaf production for the period 1960-1967.

\footnotetext{
* Econometric System Simulation Program, Duke University.

Presented at the XV International Meeting of the Institute of Management Sciences in Cleveland, Ohio on September 12, 1968. This research was supported by National Science Foundation Grant GS-1926.

${ }^{1}$ We are currently working toward the incorporation of the Burley leaf market into the model.
}

Flue-cured is produced mainly in North Carolina, South Carolina, Virginia, and Georgia.

Table 1. - Leaf Production and Acreage in United States AND Puerto Rico, 1960-1967

\begin{tabular}{cccccc}
\hline \hline & \multicolumn{2}{c}{ Total of All Tobacco } & & \multicolumn{2}{c}{ Flue-Cured } \\
\cline { 2 - 3 } \cline { 5 - 6 } $\begin{array}{c}\text { Crop } \\
\text { Year }\end{array}$ & Acreage & $\begin{array}{c}\text { Production } \\
\text { (1000 lbs) }\end{array}$ & & Acreage & $\begin{array}{c}\text { Production } \\
\text { (1000 lbs) }\end{array}$ \\
\hline 1960 & $1,169,710$ & $1,971,355$ & & 691,760 & $1,250,635$ \\
1961 & $1,201,010$ & $2,091,773$ & & 698,470 & $1,257,891$ \\
1962 & $1,252,230$ & $2,350,130$ & & 729,800 & $1,408,448$ \\
1963 & $1,205,430$ & $2,375,559$ & & 694,470 & $1,371,462$ \\
1964 & $1,108,370$ & $2,265,628$ & & 627,570 & $1,387,804$ \\
1965 & 993,650 & $1,870,483$ & & 562,300 & $1,058,970$ \\
1966 & 985,970 & $1,900,431$ & & 609,300 & $1,108,970$ \\
1967 & 989,340 & $2,018,699$ & & 626,860 & $1,267,851$ \\
\hline
\end{tabular}

SoURCE: U.S. Department of Agriculture Consumer and Marketing Service. Annual Report on Tobacco Statistics, 1967, table 1.

Flue-cured leaf markets open annually in July and August. The leaf is brought by the growers to the auction warehouses. It is then placed in flat baskets and arranged in rows on the auction floor.

When the auction begins, the auctioneer, the warehouseman and his clerks walk along one side of the row, the buyers' representatives on the other side. The warehouseman begins the proceedings with a starting bid on a particular pile of tobacco. The auctioneer then takes up his chant, the buyers recording their bids by nods, winks or gestures until the maximum bid consummates the sale $[20$, p. 258].

The selling side of the leaf market consists of a very large number of growers. ${ }^{2}$ However, the buying side is quite different. Tobacco buyers are either representatives of the domestic cigarette manufacturers or are buyers for export. Table 2 is included to give an indication of the concentration of the cigarette manufacturing industry. The buying side of the leaf market can reasonably be classified as oligopsonistic. A number of studies have been made in an effort to determine the extent to which the buying side behaves competitively [16, 20 , 25]. The results are inconclusive, although one hypothesis which has been put forth is that

\footnotetext{
${ }^{2}$ For example, the number of acreage allotments under the government control program for flue-cured leaf in 1967 was 194, 475 [26, table 5].
} 
Table 2. - Market Shares of Domestic Cigarette SALES, 1966

\begin{tabular}{lc}
\hline \multicolumn{1}{c}{ Firm } & Market Share in Per Cent \\
\hline R. J. Reynolds & 32.6 \\
American Tobacco & 24.4 \\
Brown and Williamson & 14.0 \\
Philip Morris & 10.8 \\
P. Lorillard & 9.1 \\
Liggett and Meyers & 8.8 \\
United States Tobacco & 0.1 \\
Larus and Brother & 0.1 \\
Stephans Brothers & 0.1 \\
Total & $\mathbf{1 0 0 . 0}$ \\
\hline
\end{tabular}

SOURCE: Printers' Ink, 1966.

of "percentage buying" [16]. This hypothesis states that the buyers are more concerned with insuring that other buyers pay the same price for leaf inputs than they are in obtaining the minimum (oligopsonistic) price. Given this behavioral pattern, it becomes more acceptable to estimate a demand function for tobacco.

Table 3 is presented to indicate the importance of foreign trade in both tobacco leaf and cigarettes. Of total imports of tobacco leaf, about 80 per cent is for use in the manufacture of cigarettes. The remainder is used for cigar manufacture. Foreign leaf accounts for about 12 per cent of the tobacco in an average domestic cigarette. And, of total flue-cured leaf produced in 1967 in the United States, about onethird was exported.

Since 1933 the United States government
Table 3. - Tobacco Foreign Trade OF UNITED States IN 1967

\begin{tabular}{ccc}
\hline & Exports & Imports \\
\hline Flue-cured (1000 lbs) & 427,435 & \\
Burley (1000 lbs) & 46,060 & \\
Other types (1000 lbs) & 98,780 & \\
Total & $\frac{572,275}{196,700}$ & $\mathbf{1 9}$ \\
Cigarettes (millions) & $23,652.0$ & $\mathbf{1 2 . 1}$ \\
\hline Source: U.S. Department of Agriculture Consumer and Mar- \\
keting Service. Annual Report on Tobacco Statis- \\
tics, 1967, table 35.
\end{tabular}

has intervened in the operation of the tobacco leaf market [3]. This intervention consists of two basic controls: (1) output restriction and (2) support prices. The existence of these controls has created an effective monopoly on the selling side of the leaf market. In fact, the controls are often justified on the grounds that monopoly power is necessary to offset oligopsony on the buying side. In any event, the most difficult problem we have encountered in building the model has been the treatment of the two government control or policy variables, viz., acreage allotment, (AL), and support price, (SP). We turn now to the econometric model.

\section{The Model}

The variables of the model are defined below. Further explanation of the variables is given in the discussion of the individual equations.

\section{Variables $^{3}$}

\section{Endogenous Variables}

1. $A F R$

2. $A V A L$

3. AFRMAL

4. UND

5. $A$
Free market acreage

(acres)

Acre value

(dollars)

Free market acreage less allotment

(acres)

Underage

(acres)

Actual acreage

(acres)
Artificial Series — Estimated

From identity

From identity

From identity

Annual flue-cured acres. Source: Annual Report on Tobacco Statistics

\footnotetext{
${ }^{3}$ All pounds are in farm-sales equivalent weights. All variables refer to the current year $t$, unless otherwise indicated.
} 
6. $Q$

7. QNET

8. SQNET

$9 S Q$

10. $P A C T$

11. $P F R$

12. $S P M F P$

13. $T$

14. $C C O N$

15. $C P R O$

16. $L F P C I G$

17. $C D I S$

18. DDISP

19. $S T K$

Exogenous Variables

1. OTHDIS

2. $P C A P Y$

3. $R D I S Y$

4. $R P C I G$
Leaf production

(1000 lbs)

Leaf production less leaf pledged (1000 lbs)

Ratio of net leaf supply to domestic disappearance (or usage)

Ratio of leaf supply less exports only to domestic disappearance (or usage)

Leaf price (cents)

Free market leaf price (cents)

Support price minus free market price

(cents)

Leaf pledged by growers at support price

(1000 lbs)

Cigarette consumption

(billions cigarettes)

Cigarette production

(billions cigarettes)

Leaf per cigarette (lbs/1000 cigarettes)

Disappearance (usage) into cigarette production (1000 lbs)

Domestic leaf disappearance (usage)

(1000 lbs)

Stock of leaf at end of crop year (1000 lbs)

Disappearance into other products

(1000 lbs)

Disposable income per capita (dollars)

Real disposable income (billion dollars)

Real price of cigarettes retail (cents/pack)
Annual flue-cured leaf produced. Source: Annual Report on Tobacco Statistics

From identity

From identity

From identity

Average annual flue-cured price. Source: Annual Report on Tobacco Statistics

Artificial series - estimated

From identity

Source: Agricultural Statistics

Annual domestic cigarette consumption. Source: Agricultural Statistics

Source: Agricultural Statistics

Source: Annual Report on Tobacco Statistics

Source: Annual Report on Tobacco Statistics

Annual amount of leaf which disappears from stock. Source: Annual Report on Tobacco Statistics

Source: Annual Report on Tobacco Statistics

Source: Annual Report on Tobacco Statistics

Source: Economic Report of the President

Source: Economic Report of the President

Average cigarette price deflated by consumer price index.

Source: Bureau of Labor Statistics 
5. TIME

6. $T X F W D$

7. $W P X$

8. $X$

9. $Y P A$
Time

Tax free withdrawals and exports

(billions cigarettes)

Wholesale price index

Exports of leaf

(1000 lbs)

Yield per acre

$1949=1$

Source: Agricultural Statistics

Source: Economic Report of the President

Source: Annual Report on Tobacco Statistics

Average annual amount of fluecured leaf produced per acre. Source: Annual Report on Tobacco Statistics

\section{Policy Variables}

1. $A L$

2. $L B D M Y$

3. $S B D M Y$

4. $S P$
Allotment of acres

(acres)

Dummy variable for first year poundage program

Dummy variable for Soil Bank

Support price

(cents)
Source: Annual Report on Tobacco Statistics

Equals 1 in 1965 and zero otherwise

Equals 1 in 1957, 1958 and zero otherwise

Source: Annual Report on Tobacco Statistics
The model consists of 19 equations which represent the tobacco industry over the period 1949-1966. Since the model is recursive, the seven behavioral equations $(1,4,10,11,13,14$, and 16) were estimated by ordinary least squares. ${ }^{4}$ The remaining twelve equations are identities. It is convenient to consider the model in three blocks. The first block of six equations explains total leaf production and the effect of the government restriction on output. The second block, equations 7-13, describes the determination of leaf price and the effect of the government support price. The third block, equations 14-19, is concerned with the cigarette manufacturing portion of the industry.

To illustrate the order in which the blocks must be solved and to provide an initial overview of the model, we have included a flow chart (figure 1). As indicated in the chart, blocks $\mathrm{A}$ and $\mathrm{C}$ must be solved first for the values of $Q$ and DDISP, and then block $B$ may be solved for the remaining variables. ${ }^{5}$ Bars are placed over predetermined variables.

\footnotetext{
* Two of these seven equations describe the behavior of artificial, or hypothetical, endogenous variables. The construction of the two equations (1 and 11) is described fully in the following sections.

${ }^{5}$ Equation 2, the definitional equation of the variable
}

\section{A Leaf Production}

The justification for treating leaf production separately from price determination is that the tobacco leaf market is of the cobweb type. That is, price and production are not determined simultaneously. Rather, production depends upon lagged price and can be determined first. Since price depends upon current production, it can logically be determined after production has been fixed. In more concrete terms, tobacco growers decide on leaf production in the Spring based upon the price received for the crop in the preceding Fall. The tobacco is then harvested in July and August and taken to market. Since the growers normally have no storage capability, the leaf production is thrown upon the market in perfectly inelastic supply (modified somewhat by the control program).

We have found it useful to treat the average amount of leaf produced per acre, $Y P A$, as exogenous to the model. That is, YPA depends largely upon weather, technical change and, since $1965, Y P A$ has been subject to govern-

$A V A L$, could have logically been placed in block B rather than in block $A$ since its current value cannot be found until block $\mathrm{B}$ is solved. However, only the lagged value of $A V A L$ is needed in any other equations, and we prefer to place it in block $\mathrm{A}$ for economic reasons. 
Figure 1. - Flow Chart of Tobacco Model

A. Leaf Production
1. $A F R$
$=A F R\left(\bar{A}_{t-1}, \overline{A V A L_{t-1}}\right)$
2. $A V A L$
$=\frac{\overline{Y P A} \times P A C T}{\overline{W P X}}$
3. $A F R M A L=A F R-\overline{A L}$
4. UND = UND (AFRMAL)
5. $A=\overline{A L}-U N D$
6. $Q$
$=A \times \overline{Y P A}$

B. Leaf Price
7. $Q N E T=Q-T$
8. SQNET $=\frac{\overline{S T K}_{t-1}+Q N E T-\bar{X}}{D D I S P}$
9. $S Q$
$=\frac{\overline{S T K}_{t-1}+Q-\bar{X}}{D D I S P}$
10. $P A C T=$ PACT (SQNET, $\overline{P C A P Y})$
11. $P F R=P F R(S Q, \overline{P C A P Y})$
12. $S P M F P=\overline{S P}-P F R$
13. $T=T(S P M F P)$

C. Cigarettes

DDISP
14. $\operatorname{CCON}=\operatorname{CCON}(\overline{\mathrm{RPCIG}}, \overline{\mathrm{RDISY}})$

15. $C P R O=C C O N+\overline{T X F W D}$

16. $L F P C I G=L F P C I G \overline{(T I M E)}$

17. $C D I S=(L F P C I G \times C P R O) 1000$

18. $D D I S P=C D I S+\overline{O T H D I S}$

19. $S T K=S T K_{t-1}+Q-D D I S P-\bar{X}$

mental limitation. If price is multiplied by $Y P A$ we obtain the variable acre-value, $A V A L$. Consequently, we view the grower as possessing a supply function of acreage, $A$, which responds to the lagged price of acres, or $A V A L_{t-1}$. Under free market conditions we would like to estimate the acreage equation, $A=f\left(A V A L_{t-1}\right)$. For example, the line $O B$ in figure 2 could represent such an equation.
FIGURE 2. -

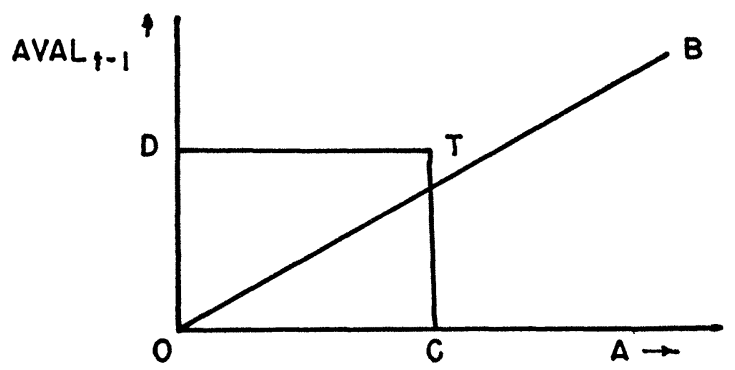

There would be no problem in estimating $O B$ if we had reason to believe that all observable points actually lie on $O B$. Unfortunately, we have reason to believe otherwise. If the government should have set the allotment for acreage at $O C$ acres when $A V A L_{t-1}$ was $O D$, then the point observed in that year would have been point $T$. Clearly, point $T$ does not lie on the acreage supply equation.

To avoid this difficulty we have employed a strategy proposed by Johnson [12] in a study of the Burley market. Rather than attempting to estimate $A$, we estimate the difference between $A$ and acreage allotment $A L$. This difference or underage, $U N D$, is the number of acres not planted even though permitted by the allotment. The hypothesis is that $U N D$ will be lower the greater the economic incentive is to growers. Although Johnson used the lagged price of leaf as the economic incentive variable, we have used a different approach. Before describing this approach we might point out that the use of lagged price appears to have the defect that $A L$ is not accounted for. That is, $U N D$ might be zero in year 1 and 500 in year 2 even though the lagged price was constant, simply because the level of $A L$ varied.

Our strategy is to estimate a hypothetical free market acreage, $A F R$, and to use the excess of $A F R$ over $A L$ as a measure of the growers' incentive to reduce $U N D$. The $A F R$ equation was estimated by using 1910-1930 data. Thus, since the government control program did not go into effect until after 1933, the 1910-1930 data points should all lie on the line $O B$ in figure 1 . Of course, in using the equation we must make the rather strong assumption that the structure of supply has not changed over this long period of time. The excellent statistical results for these equations offer some support for this assumption. 
Based upon the hypothesis that $A$ depends upon the expected $A V A L$, we can develop $A$ as a function of $A_{t-1}$ and $A V A L_{t-1}$ [4, p. 206]. Equation 1 is the acreage equation estimated with 1910-1930 data. Since it will be used in the model to generate acreages for the 19491966 period which would have occurred had the free market structure of 1910-1930 prevailed, we will label it the free market acreage equation. The only other behavioral equation in the first six is equation 4 , the underage equation. We have already discussed the explanation for regressing $U N D$ on the excess of $A F R$ over $A L$, or $A F R M A L$. As hypothesized, the coefficient of $A F R M A L$ is negative and is statistically significant.

One further point should be made about the $U N D$ equation. Two dummy variables were used to account for unusual events affecting $U N D$. One dummy variable represents the effect of the Soil Bank program which was in effect in 1956, 1957, and 1958. Since the program was announced too late in 1956 to affect growers' decisions, the dummy variable $S B D M Y$ represents 1957 and 1958 only. The second dummy variable, $L B D M Y$, represents the effect of a change in allotment after planting was over in 1965. The original allotment was set at 515,425 acres in December 1964. However, in May 1965 the allotment was increased to 607,335 acres as a result of the passage of a new government control program (the new program permits control of poundage as well as acreage).

1) Free-Market Acreage

$$
\begin{aligned}
A F R=- & 197.6045+0.9089 \bar{A}_{t-1} \\
& (89.0672)(0.0738) \\
& +3.1058 \overline{A V A L}_{t-1} \\
& (0.8684) \\
\bar{R}^{2}= & 0.9025 \\
D W= & 2.1439 \\
S E= & 84.5436
\end{aligned}
$$

2) Acre Value

$$
A V A L=\frac{\overline{Y P A} \times P A C T}{\overline{W P X}}
$$

3) Free-Market Acreage Less Allotment

$$
A F R M A L=A F R-\overline{A L}
$$

4) Underage

$$
\begin{aligned}
U N D= & 26.9640-0.0160 \text { AFRMAL } \\
& (6.6716)(0.0085) \\
+ & 46.3971 \text { SBDMY } \\
& (5.2275) \\
& +33.6419 \text { LBDMY } \\
& (7.5373) \\
\bar{R}^{2}= & 0.8296 \\
D W= & 1.5642 \\
S E= & 6.8986
\end{aligned}
$$

5) Actual Acreage

$A=\overline{A L}-U N D$

6) Leaf Production

$Q=A \times \overline{Y P A}$

\section{B Leaf Price}

In equations $7-13$ we attempt to integrate the government support price for leaf into the determination of price. The essence of this part of the model is that the amount of leaf pledged by growers at the support price, $T$, and the market price of leaf, $P A C T$, are mutually dependent. That is, $P A C T$ depends upon $T$ and $T$ depends upon $P A C T$.

The statement that $T$ depends upon $P A C T$ requires further explanation. As suggested by Johnson [12], we hypothesize that $T$ depends upon the difference between $S P$ and the hypothetical free market price, $P F R$. Thus, $P F R$ is analogous to $A F R$ since it represents what the price would have been if the government control program had not been in effect. Since we used the parameter estimates from the $P A C T$ equation to generate the artificial $P F R$ series (to be described below), it is in this special sense that we view $T$ and $P A C T$ as simultaneously determined. While we would have preferred a simultaneous estimation of the $T$ and $P A C T$ equations, this was not possible because of the nonexistence of actual data on $P F R$.

We now turn to equation 10 , the $P A C T$ equation, in order to explain the derivation of the free market price, $P F R$. First, however, we need to explain the explanatory variables used.

A number of studies of the tobacco industry $[8,15,20,25]$ have all found that an important variable in explaining price is a variable re- 
sembling our SQNET. This variable is the ratio of the total supply of leaf available to total usage of leaf, or disappearance. As such, $S Q N E T$ represents an inventory stock to sales ratio concept. Cigarette manufacturers have often stated that they seek to maintain a ratio of total supply of leaf to current usage of about 2.5 to 1 [20]. A main reason for such large inventories is the $2-3$ year aging requirement of tobacco leaf. The numerator of the variable $S Q N E T$ is equal to the sum of the stock of tobacco on hand at the beginning of the market period and leaf production minus exports and minus tobacco pledged under the support program, $T$. The numerator is then divided by the current domestic usage of tobacco leaf, DDISP. The expectation that the coefficient of this variable in the $P A C T$ equation should be negative is confirmed by the statistical results.

The second variable, $P C A P Y$, is an income variable which accounts for shifts in demand over the period. It has a positive coefficient as expected. Perhaps the most serious omission is a variable to account for the quality of leaf. Unfortunately, we have been unable to obtain such a variable.

The derivation of $P F R$ from equation 10 is accomplished by setting $T$ equal to zero. That is, if the government is not intervening in the market, total pledges of leaf will be zero. Hence, equation 11 is simply equation 10 with $T$ set equal to zero. $P F R$ is always less than $P A C T$, as expected.

Equation 13 is the $T$ equation. The goodnessof-fit of this equation, as measured by the coefficient of determination, is poorer than for any of the other equations. However, the regression coefficient is of the expected sign and is statistically significant. We should also mention that in estimating the equation a value of $P F R$ was used which differs slightly from the $P F R$ given in equation 11. The "adjusted" $P F R$ used was determined by first calculating a predicted difference between $P A C T$ and $P F R$ for each year by subtracting equation 11 from equation 10. Then, the predicted difference was subtracted from the observed market price to obtain "adjusted" $P F R$.

\section{7) Leaf Production Less Leaf Pledged $Q N E T=Q-T$}

8) Ratio of Net Leaf Supply to Domestic Disappearance

$S Q N E T=\frac{\overline{S T K}_{t-1}+Q N E T-\bar{X}}{D D I S P}$

9) Ratio of Leaf Supply Less Exports to Disappearance

$S Q=\frac{\overline{S T K}_{t-1}+Q-\bar{X}}{D D I S P}$

10) Actual Leaf Price

$\log P A C T=-0.2833 \log S Q N E T$

(0.1108)

$$
+0.5858 \log \overline{P C A P Y}
$$$$
\text { (0.0189) }
$$

$\bar{R}^{2}=0.7873$

$D W=1.6657$

$S E=0.0435$

(1949-1966)

11) Free-market Leaf Price

$\log P F R=-0.2833 \log S Q$

$$
+0.5858 \log \overline{P C A P Y}
$$

Note: $P F R$ is an artificial series derived using parameter estimates in equation 10. Actual data on $P F R$ does not exist.

12) Support Price Less Free-market Price

$$
S P M F P=\overline{S P}-P F R
$$

\section{3) Leaf Pledged under Support Program}

$$
\begin{aligned}
& \log T=\underset{(0.1609)}{5.4038}+\begin{array}{c}
0.1472 \\
(0.0352)
\end{array} \text { SPMFP } \\
& \bar{R}^{2}=0.4922 \\
& D W=1.2729 \\
& S E=0.4393
\end{aligned}
$$

\section{Cigarettes}

Equation 14 is the demand function for cigarettes. In view of the oligopolistic pricing behavior of the cigarette manufacturers it seems reasonable to take the price of cigarettes as exogenous. However, this is one part of the model which we expect to improve later by adding equations and perhaps by treating price as endogenous.

The demand function displays properties similar to those which have been obtained by a number of other investigators. For example, the price elasticity of demand for cigarettes is -0.43 and the income elasticity is 0.77 . According to Sackrin [21], other analyses have shown that the price elasticity of demand for 
cigarettes is between -0.3 and -0.4 , and the income elasticity of demand about 0.5. A dummy variable used to represent the 1964 Surgeon General's report on the link between cancer and smoking proved to be insignificant.

The other estimated equation in this block is the technical relation between leaf disappearance and cigarette production. Thus, equation 16 is a regression of tobacco leaf per cigarette, $L F P C I G$, on time. It reveals that $L F P C I G$ is declining exponentially at about 3 per cent per year. The ratio of flue-cured leaf price to Burley price was also tried as an independent variable, but it proved to be statistically insignificant.

\section{4) Domestic Cigarette Consumption}

$$
\begin{aligned}
& \log C C O N=-0.4250 \log \overline{R P C I G} \\
&(0.1349) \\
&\left.+\begin{array}{c}
0.7721 \\
(0.0765)
\end{array}\right) \\
& \bar{R}^{2}=0.9094 \log \overline{R D I S Y} \\
& D W=0.5900 \\
& S E=0.0467
\end{aligned}
$$

the model for each period for the current values of the 19 endogenous variables. The values of the endogenous variables generated in one period were fed back into the model in future periods in the form of lagged endogenous variables. The error terms in the behavioral equations were suppressed. In this manner we generated the time paths for the 19 endogenous variables over the period 1949 through 1966.

The simulations were run on an IBM $360 / 75$ computer with the aid of PROGRAM SIMULATE - a simulation language developed at the University of Wisconsin for conducting simulation experiments with econometric models.

Figures 3 through 8 contain graphs of six of the variables whose time paths were simulated. For the purpose of comparisons, the actual time paths of these six variables are also plotted. On the basis of these graphical comparisons of the simulated output of the model and the actual time paths of the corresponding variables, we conclude that our model does a reasonably good job of simulating the behavior of the tobacco industry between 1949 and 1966. It remains to

Figure 3. - Flue-CURed Underage (1000 ACRes)

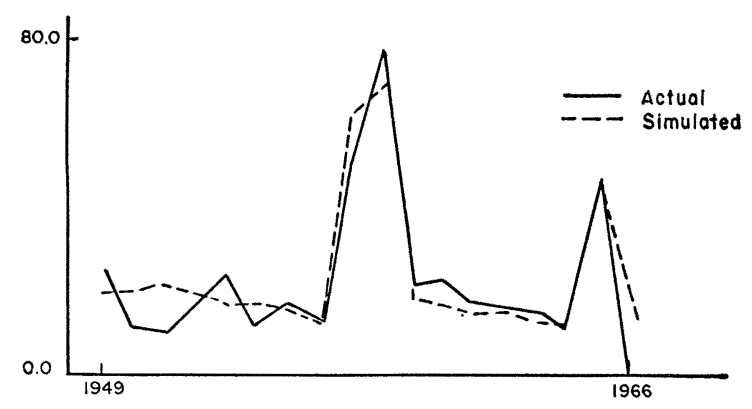

Figure 4. - Stocks of Flue-cured Tobacco Leaf (1000 LBS)

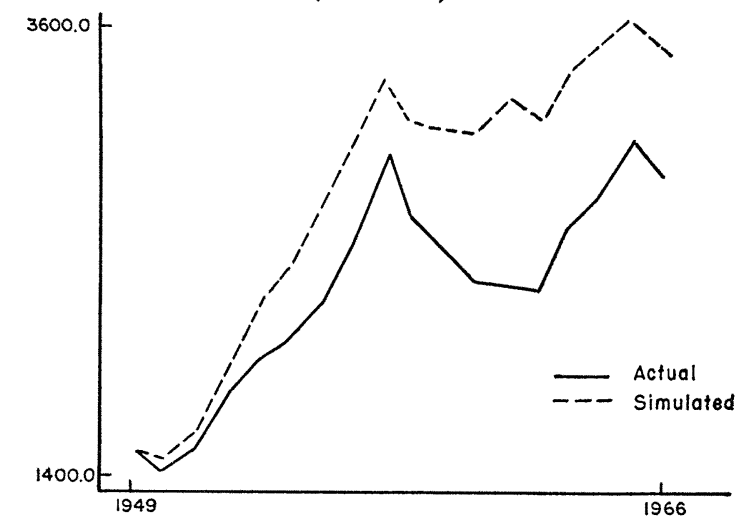


Figure 5. - Actual Price of Flue-cured Tobacco LEAF (CENTS)

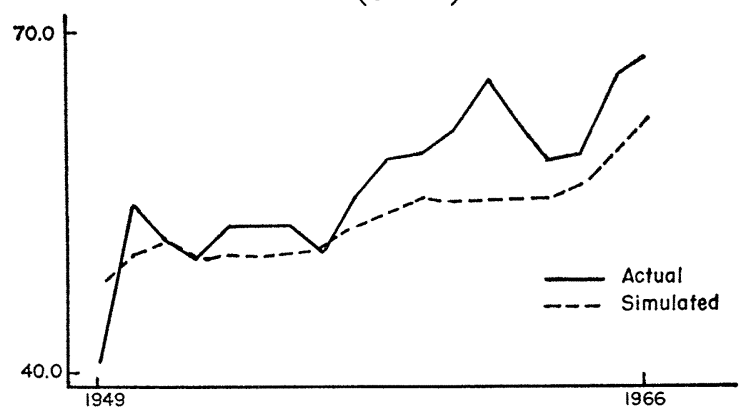

Figure 6. - Volume of Flue-cured Tobacco Leaf Pledged by Growers at Support Price (1000 Lbs)

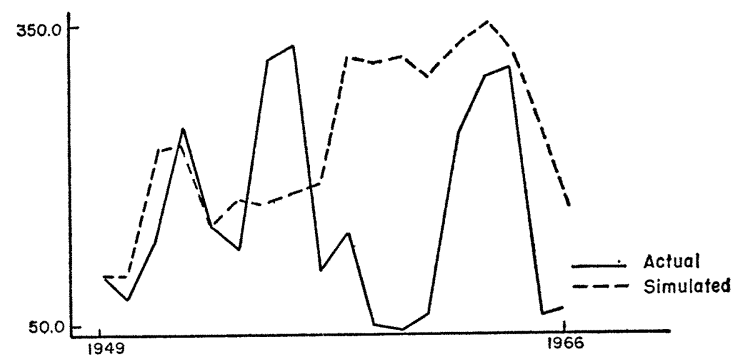

Figure 7.-Domestic Cigarette Consumption (UNited States) (BILlions Cigarettes)

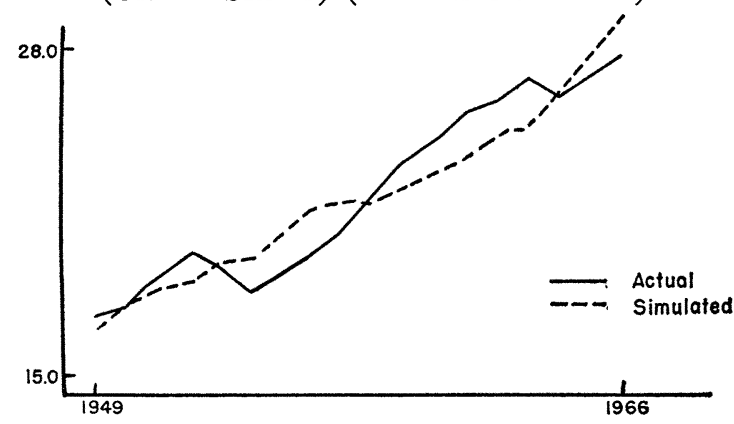

Figure 8. - Flue-cured Tobacco Leaf per 1000 Cigarettes (LBS/1000 Cigarettes, Ratio estimate)

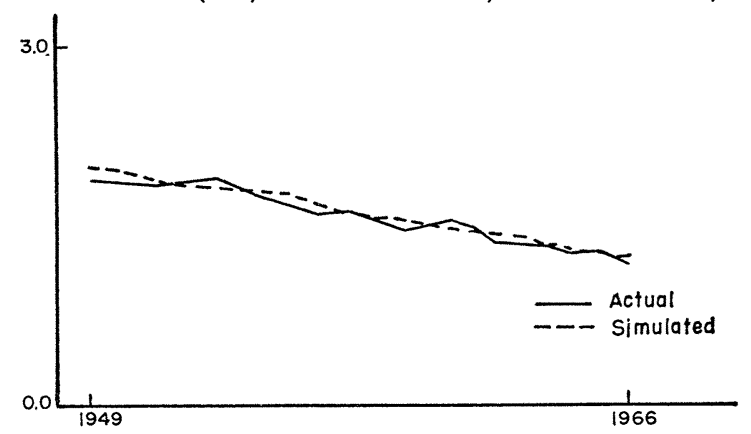

be seen how well the model will predict the future.

Of course, a number of more sophisticated techniques exist for validating simulation models. For example, in an earlier study of the textile industry, Naylor, Sasser, and Wallace [17] used spectral analysis and analysis of variance to validate an econometric model.

\section{REFERENCES}

[1] An Economic Impact Study of the Tobacco Industry. Arlington, Va.: C.E.I.R., Inc., 1964.

[2] Benedict, M. R., and O. C. Stine, The Agricultural Commodity Programs (New York: The Twentieth Century Fund, 1956).

[3] Brooks, R. C., and J. C. Williamson, Jr., FlueCured Tobacco Programs, 1933-1958. A. E. Information Series No. 66, North Carolina State College, Raleigh, 1958.

[4] Christ, C. F. Econometric Models and Methods (New York: John Wiley and Sons, Inc., 1966).

[5] Cohen, K. J., Computer Models of the Shoe, Leather, Hide Sequence (Englewood Cliffs, N.J.: Prentice-Hall Inc., 1960).

[6] Cyert, R. M., and J. G. March, A Behavioral Theory of the Firm (Englewood Cliffs, N.J.: Prentice-Hall Inc., 1963).

[7] Gage, C. F., American Tobacco: Types, Uses, Markets. United States Department of Agriculture. Bureau of Agricultural Economics. Circular No. 249. (Jan., 1933).

[8] Goris, H., Price-Determining Factors in American Tobacco Markets (Amsterdam: North-Holland Publishing Company, 1954).

[9] Haenszel, W., M. B. Shimkin and H. P. Miller, Tobacco Smoking Patterns in the United States. United States Department of Health, Education and Welfare. U.S. Public Health Service. Public Health Monograph No. 45 (May, 1956).

[10] Heady, E. O., and J. L. Dillion, Agricultural Production Functions (Ames: Iowa State University Press, 1961).

[11] Heady, E. O., and L. G. Tweeten Resource Demand and Structure of the Agricultural Industry (Ames: Iowa State University Press, 1963).

[12] Johnson, G. L., Burley Tobacco Control Programs. Bulletin 580, Kentucky Agricultural Experiment Station, Lexington (Feb., 1952).

[13] Johnston, J., Econometric Methods (New York: McGraw-Hill Book Company, 1963).

[14] Fisher, F. M., A Priori Information and Time Series Analysis (Amsterdam: North-Holland Publishing Company, 1962).

[15] Fisher, W. H., Economics of Flue-Cured Tobacco. Federal Reserve Bank of Richmond, 1945.

[16] Jackson, E. L., The Pricing of Cigarette Tobaccos (Gainesville: University of Florida Press, 1955). 
[17] Naylor, T. H., W. H. Wallace, and W. E. Sasser, "A Computer Simulation Model of the Textile Industry," Journal of the American Statistical Association (Dec., 1967).

[18] Naylor, T. H., et al., Computer Simulation Techniques (New York: John Wiley and Sons, Inc. 1966).

[19] Nerlove, M., The Dynamics of Supply: Estimation of Farmers' Response to Price (Baltimore: The Johns Hopkins Press, 1958).

[20] Nicholls, W. H., Price Policies in the Cigarette Industry (Nashville: Vanderbilt University Press, 1951).

[21] Sackrin, S. M., "Factors Affecting the Demand for Cigarettes," Agricultural Economics Research. United States Department of Agriculture. Economic Research Service, vol. XIV (July, 1962).

[22] Sanderson, F. H., Methods of Crop Forecasting. (Harvard Economic Studies No. 93) (Cambridge: Harvard University Press, 1954).
[23] Suits, D. B., "An Econometric Model of the Watermelon Market," Journal of Farm Economics, XXXVII (May, 1955).

[24] Suits, D. B., and S. Koizumi. "The Dynamics of the Onion Market," Journal of Farm Economics, XXXVIII (May, 1956).

[25] Tennant, R. B., The American Cigarette Industry (New Haven: Yale University Press, 1950).

[26] United States Department of Agriculture. Consumer and Marketing Service. Annual Report on Tobacco Statistics. (Selected years, 1946-1967).

[27] United States Department of Agriculture. Agricultural Statistics, 1967 and selected previous years. (Washington: U.S. Government Printing Office, 1967).

[28] Williamson, J. C., Jr., and R. C. Brooks, Poundage Quota Controls for Flue-Cured Tobacco. A. E. Information Series No. 83, North Carolina State College, Raleigh, 1961. 